\title{
ARCA E IRA. CoN/VERSACIONES EN TIEMPOS DE DESHUMANIZACIÓN Miguel Rocha Vivas*
}

\author{
Editorial Universidad de Guadalajara, \\ Guadalajara, 2019, 288 P. \\ Sebastián Díaz Martínez ${ }^{1}$
}

\footnotetext{
* Cómo citar esta reseña: Díaz Martínez, S. (2021). Reseña del libro Arca e Ira. Con/ versaciones en tiempos de deshumanización de Miguel Rocha Vivas. Estudios de Literatura Colombiana 48, pp. 325-327. DOI: https:// doi.org/10.17533/udea.elc.n48a22

1 https://orcid.org/0000-0001-8989-3412 sdiazmartinez@gradcenter.cuny.edu The City University of New York, United States
}

Editores: Andrés Vergara Aguirre, Christian Benavides Martínez, Valentina Noreña Gómez

Recibido: 15.08 .2020

Aprobado: 09.11.2020

Publicado: 18.12.2020

Copyright: (2021 Estudios de Literatura Colombiana. Este es un artículo de acceso abierto distribuido bajo los términos de la Licencia Creative Commons AtribuciónNo comercial - Compartir igual 4.0 Internacional

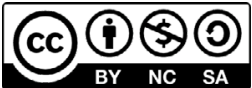

Desde hace unas décadas se ha trazado el pensamiento posthumanista enmarcando teóricamente las discusiones en el campo literario. Descentralizar lo humano, a partir de problematizar el dispositivo de la especie como epicentro de la representación y la producción epistemológica, traza un antes y un después en los acercamientos teóricos a la literatura. El pensador colombiano Miguel Rocha Vivas, premio Casa de las Américas en Estudios sobre culturas originarias (2016), en su libro Arca e Ira. Con/versaciones en tiempos de deshumanización (Editorial Universidad de Guadalajara), desarrolla de manera muy original las inquietudes del posthumanismo en la escena teórico-literaria en Colombia desde la crítica a la sistemática deshumanización en el proyecto neoliberal global.

El libro es un arriesgado laboratorio de pensamiento. Transita, desde el perenne marco del diálogo, en una reflexión dual que indaga en los problemas cruciales que definen lo "humano"; y, desde distintos usos formales, tales como la escritura autorreferencial, la crítica, la teoría y la poesía, postula intensos análisis sobre las relaciones entre 
el ser humano con la naturaleza, la animalidad, lo vegetal y por supuesto con la humanidad misma.

$\mathrm{El}$ ininterrumpido uso de la con(/)versación es un gesto que el autor realiza para desmarcarse de las formas tradicionales de producción crítica y teórica. Un claro ejemplo de ello es la misma definición de conversación como un juego de palabras desde su binarismo morfológico: conversar como versar-con, pensar con el otro. Así, desde las mismas estrategias estilísticas hay un posicionamiento frente al tema central que aborda el libro: lo humano. Dicha perspectiva propone entender la teoría, la crítica y la literatura desde un umbral dialógico. Producimos saberes y diálogos en conversación con el otro, desde posiciones y contrastes que se contradicen y complementan, y no desde la violenta homogenización que atestiguamos desde la implementación del neoliberalismo como política global.

Dicho gesto formal, el de abordar discusiones teóricas desde el uso del diálogo, también es un llamado a (re)pensar las formas donde se establecen convencionalmente sistemas epistemológicos. Los textos dialógicos, usados en la antigüedad clásica como una posibilidad para trazar complejas discusiones filosóficas, habían sido relegados en la modernidad occidental a un espacio literario, del cual convencionalmente se piensa más desde un rigor estético que reflexivo. Siendo así, el libro de Rocha es un llamado a hacer hincapié en la posibilidad de la literatura para estimular formas críticas de las complejas transformaciones globales que increpan a Colombia. Así, este libro se constituye como una apología a la con/versación, siguiendo todas las inestabilidades propias de su ejercicio (contradicciones, ideas que no se concluyen del todo, dispersión por referencias adyacentes, etc.) para proponer la experiencia del conocimiento como un ejercicio afectivo y crítico.

Los personajes, Arca e Ira, representan también comunidades diferentes en diálogo. Arca, a partir de ciertos índices que propone el libro, es de origen colombiano; mientras que Ira refiere tradicionales expresiones argentinas. Así, el diálogo de Arca e Ira crea una conversación que atraviesa todo un continente. Así, el contraste entre dos posiciones separadas geográficamente se vinculan desde los mismos problemas comunes: la sistemática destrucción de los recursos naturales desde las lógicas antropogénicas, el secuestro de identidades originarias para fetichizar mercancías comercializadas a escalas globales, la excesiva individualización de las sociedades que impide un acercamiento intenso con el otro y con otras formas de entender el mundo, el nihilismo producto del 
placer como único eje posible para la felicidad. Entre todos estos fenómenos, el libro tiene un objetivo central: crear una noción de "lo humano" que vincule experiencias desde el otro, desde la apreciación de la naturaleza lejos de su paradigma de "recurso".

Las conversaciones transcurren y evocan distintos lugares alrededor del globo. Asia, América del norte y Latinoamérica, África y la India componen el paisaje transitivo donde sucede la disputa teórica del libro. Desde el primer problema que se presenta en el libro (la conversión del "viajero" en "turista”) se propone una resistencia a la homogenización de una experiencia, como puede ser el viaje, la cual ha sido diseñada para ser reproducida sistemática y equivalentemente en lejanos contextos geográficos con el fin de estipular su capitalización y rentabilidad. Hacer de las experiencias servicios y de los lugares bienes.

Los paisajes que contienen las conversaciones entre Arca e Ira estimulan las discusiones e inquietudes que atraviesan el libro. Las personas a las que apelan integran una visión amplia, heterogénea y afectiva sobre lo humano. Así, las separaciones que atraviesan género, nación, raza, identidad, incluso el clásico binarismo entre naturaleza y cultura que sirvió de excusa para la explotación indiscriminada de recursos naturales, se hacen más opacas, más diminutas en su hegemonía ante el llamado a enfatizar la pluralidad que compone algo tan abstracto y abierto como lo humano.

El libro de Miguel Rocha colabora en insertar a Colombia en una discusión viralizada por todo el globo. Desarrolla una perspectiva multidimensional que potencia el lugar de enunciación colombiano, el cual atestigua, padece y consolida las violentas y deshumanizantes políticas neoliberales que protagonizan las políticas públicas trasnacionales. El libro es un ejercicio intenso, arriesgado y apasionante, que ante todo busca resistir coercitivos dispositivos, tácticas y políticas que operan sobre el ser humano, sus procesos de sujeción, su intimidad. Rocha insta a resignificar el concepto de lo "humano" para articularlo como un concepto que vincula y reconoce pluralidades de cosmovisiones y de formas de estar en el mundo. Enfatizar la abstracción de "humanidad", ante todo, como el despliegue de la posibilidad de comunidad. Siendo así, es importante enfatizar en las reflexiones que se escapan de los umbrales formales y epistemológicos convencionales en la producción teórica nacional, con el fin de proponer análisis de la literatura y de la cultura por parte de instituciones, redes y colaboraciones investigativas ceñidas por una deliberada crítica hacia la homogenización. A fin de cuentas, trabajar por una academia más experimental, más heterogénea, más humana. 